\title{
Causal and Logical Necessity in Malebranche's Occasionalism
}

\section{Document Version}

Submitted manuscript

Link to publication record in Manchester Research Explorer

\section{Citation for published version (APA):}

Fisher, A. R. J. (2011). Causal and Logical Necessity in Malebranche's Occasionalism. Canadian Journal of Philosophy, 41(4), 523-48.

\section{Published in:}

Canadian Journal of Philosophy

\section{Citing this paper}

Please note that where the full-text provided on Manchester Research Explorer is the Author Accepted Manuscript or Proof version this may differ from the final Published version. If citing, it is advised that you check and use the publisher's definitive version.

\section{General rights}

Copyright and moral rights for the publications made accessible in the Research Explorer are retained by the authors and/or other copyright owners and it is a condition of accessing publications that users recognise and abide by the legal requirements associated with these rights.

\section{Takedown policy}

If you believe that this document breaches copyright please refer to the University of Manchester's Takedown Procedures [http://man.ac.uk/04Y6Bo] or contact uml.scholarlycommunications@manchester.ac.uk providing relevant details, so we can investigate your claim.

\section{OPEN ACCESS}




\title{
Causal and Logical Necessity in Malebranche's Occasionalism ${ }^{1}$
}

\author{
A. R. J. FISHER
}

The famous Cartesian Nicolas Malebranche (1638-1715) espoused the occasionalist doctrine that 'there is only one true cause because there is only one true God; that the nature or power of each thing is nothing but the will of God; that all natural causes are not true causes but only occasional causes' (LO, 448, original italics). ${ }^{2}$ One of Malebranche's well-known arguments for occasionalism, ${ }^{3}$ known as, the 'no necessary connection' argument (or, $\mathrm{NNC}^{4}$ ) stems from the principle that 'a true cause... is one such that the mind perceives a necessary connection between it and its effect' (LO, 450). I formulate this principle as follows:

(NC) $c$ is a true cause of $e$ iff the mind perceives a necessary connection between $c$ and $e$.

This principle permits one to undermine a purported causal relation between $c$ and $e$ (where $c$ is the purported cause, and $e$ is the purported effect) by conceiving of a case where $c$ occurs and $e$ fails to follow. If the mind perceives a necessary connection between $c$ and $e$, then it is impossible to conceive of $c$ 's occurring without $e$ 's occurring. For Malebranche, 'the mind perceives a necessary connection only between the will of an infinitely perfect being and its effects. Therefore, it is only God who is the true cause and who truly has the power to move bodies' (LO, 450). This argument regards causation as some sort of 'necessary connection' between cause and effect, where the cause is a necessary and sufficient condition for the effect and/or the effect is a necessary consequence of the cause.

Malebranche's other main argument for occasionalism is known as the 'conservation is but continuous creation' argument (hereafter, CCC). CCC attempts to undermine the causal efficacy of minds and bodies by arguing that God's causal power is necessary (and sufficient) for the existence of substances

\footnotetext{
${ }^{1}$ Thanks to Kris McDaniel, Walter Ott and Kara Richardson for detailed comments on earlier versions of this paper. I also thank Melissa Frankel for our discussions of Malebranche from which the main ideas of this paper came, and especially thank two anonymous referees for helpful suggestions and critical comments that substantially improved the paper.

${ }^{2}$ Throughout this essay I use Malebranche, N. 1997 [1674-5]. The Search after Truth. T. Lennon \& P. Olscamp, Trans. Cambridge: Cambridge University Press. Cited in text as (LO, pg.); Malebranche, N. 1997 [1688]. Dialogues on Metaphysics and on Religion. D. Scott, Trans. Cambridge: Cambridge University Press. Cited in text as (D, pg.); Malebranche, N. 1992 [16801]. Treatise on Nature and Grace. P. Riley, Trans. Oxford: Clarendon Press. Cited in text as (T, pg.).

3 In this essay the type of occasionalism I am concerned with applies to body-body, body-mind, mind-body and mind-mind causation in the natural world.

${ }^{4}$ (Nadler 1996) coined the term 'no necessary connection' for this argument and I will abbreviate accordingly, cf. (Lee 2008, 542, n. 7).
} 
and their determinate modes. God cannot create/conserve some body call it $A$ through his will or volition without locating $A$ somewhere, 'here, there, or elsewhere' (D, 115). Necessarily, if God creates/conserves some $A$, then $A$ is created/conserved at some location $l$. Theodore, on Malebranche's behalf, remarks,

'Now it is a contradiction that God wills this armchair to exist, unless He wills it to exist somewhere and unless, by the efficacy of His will, He puts it there, conserves it there, creates it there' $(\mathrm{D}, 116)$.

Now suppose God wills ball $A$ at $l$. Suppose further that $A$ is moved such that $A$ hits ball $B$ which is at rest. For Malebranche, $A$ does not move $B$. The motive force at work here does not belong to the body, but rather the force of the moving body is simply the will of God conserving each body successively in different places. ${ }^{5}$

There are two main competing interpretations of the status of NNC and its relationship with CCC. The first interpretation regards CCC as the 'most powerful and sweeping argument for God as the sole agent in the universe' (Nadler $2000,126)$, and regards NNC as the 'thin' argument that is trivial and stipulative in character (Pyle 2003, 97-8). Sukjae Lee (2008) goes so far as to claim that Malebranche himself was unhappy with the argument and proceeded to lessen its prominence in the Dialogues on Metaphysics and on Religion (hereafter, Dialogues) (Lee 2008, 540). This interpretation further claims that the 'necessary connection' principle behind NNC was deeply controversial and rejected outright by Malebranche's contemporaries (Lee 2008, 544; Pyle 2003, 100-1). Call this, the Lee-Pyle interpretation.

The opposing interpretation regards NNC and not CCC as 'the most powerful and intriguing argument for occasionalism' (Jolley 2006, 119), and 'if one grants the premise that cause and effect are necessarily connected, the argument is ingenious and even persuasive' (Loeb 1981, 205). ${ }^{6}$ This interpretation is further strengthened by the fact that Malebranche's contemporaries were also committed to the premise that God's will is necessarily efficacious. Call this, the Jolley-Loeb interpretation.

The outline of this paper is as follows. I explicitly layout NNC and articulate some of its prima facie strengths $(\mathbb{S} 1)$. I then critically discuss, what I take to be, the two main arguments against $\mathrm{NNC}$ of the Lee-Pyle interpretation (\$2). The main conclusion from $\$ 2$ is that Malebranche did not abandon NNC in his later works given textual evidence from the Dialogues, contrary to the Lee-Pyle interpretation. In $\$ 3$ I discuss in what ways Suárez, Leibniz, Régis and Spinoza all accepted the main premise of NNC. Then, I rebut Steven Nadler's influential and unchallenged criticism that Malebranche conflated causal and logical necessity, and provide a more accurate interpretation of Malebranche that only commits him to a partial reduction of causal to logical necessity ( $\$ 4)$.

For Malebranche, 'the necessity at the heart of causality is a logical one. Two things or events are causally related only if there is a logically necessary relation between them such that if the one occurs it is logically (absolutely) im-

\footnotetext{
${ }^{5}$ A further premise, of course, is required to block causal overdetermination. See Nadler's (1997, xxiii) Introduction of the Dialogues for discussion of this point.

${ }^{6}$ See also (Jolley 1990, 229).
} 
possible that the other does not follow' (Nadler 2000, 113-4, italics in original). I formulate this as follows:

(LN) the relation between cause $c$ and effect $e$ is causally necessary only if the denial of this relation implies a logical contradiction.

The dispute between the Lee-Pyle and Jolley-Loeb interpretation hinges on whether or not Malebranche's opponents accepted that causation is to be understood in terms of logical necessitation. I argue that Malebranche's opponents, in particular, the late medieval Scholastic Suárez and Spinoza accepted the view that causation involves logically necessary connections. If Malebranche's opponents view causation as logical necessitation, then NNC is after all a powerful argument for occasionalism. Therefore, it would not have been regarded as 'thin' or stipulative in the eyes of Malebranche's opponents. I further argue that Leibniz and Régis accepted a qualified version of causation as necessitation based on independently motivated theses. The dispute surrounding NNC was a lively one and not based on an outright rejection of Malebranche's conception of causation.

In the secondary literature there is a growing consensus that Malebranche's biggest mistake when he presented NNC was to conflate or equate causal with logical necessity. Nadler's (1996) accusation that Malebranche conflated causal with logical necessity has been influential on recent commentators. Nicholas Jolley who claims that Malebranche's strongest argument is NNC agrees with Nadler on this point (Jolley 1990, 229). In addition, Andrew Pyle uses the supposed conflation between causal and logical necessity to further support his construal of NNC as a weak argument (Pyle 2003, 100). I think this is a misplaced criticism of Malebranche. The assumption that there are distinct kinds of necessity is question-begging and perhaps anachronistic in this context. Even if this assumption is accepted, Malebranche does not conflate or equate causal and logical necessity; at best Malebranche partially reduces causal necessity to logical necessity since he accepts that if a relation between cause $c$ and effect $e$ holds, then it is logically necessary, but denies that if there is a logically necessary connection, then it is causally necessary. For Nadler to claim that Malebranche conflated or equated these two kinds of necessity, Malebranche has to be committed to a full reduction of causal to logical necessity so that they are equivalent. There is no textual evidence that Malebranche saw a distinction here and that he understood one kind of necessity wholly in terms of the other. Moreover, there is no reason to reject my interpretation, which I adopt from Beatrice Rome (1963), that only claims Malebranche (if he saw a distinction here at all) partially reduced causal to logical necessity. So causal necessity is not equivalent to logical necessity and thus they are not conflated.

Malebranche mounted a serious challenge to his opponents. He was simply endorsing the remnants of the medieval Aristotelian framework that was commonplace at the time amongst the late Scholastics and his fellow Cartesians, and used their principles against them. Further, Malebranche did not conflate causal and logical necessity but rather ingeniously extracted the ultimate implications of understanding causation in terms of logical necessitation. 
Malebranche introduces NNC in Book 6, pt. 2, ch. 3 of the Search where he is quick to condemn 'the most dangerous error of the philosophy of the ancients' (LO, 446). For Malebranche, if a natural event such as seasonal rain is taken to possess causal efficacy and is thus the true cause of, say, a fruitful harvest, then it is reasonable to honour and worship the seasonal rain. Malebranche sets up the context of this chapter by specifically targeting 'the ancients' whose pagan philosophy, he thinks, will 'render sovereign honour to leeks and onions' (LO, 447).

Malebranche continues by appealing to our ideas of 'mind' and 'body' 'as we should speak only of what we conceive, we should only reason according to these two kinds of ideas' (LO, 448, italics mine). For Malebranche, following Descartes, the clear idea of body is nothing more than extension and the passive capacity for local motion, and thus a priori bodies can never be the bearer of dynamic properties. Thus, finite minds are the only 'worldly' candidate for causal efficacy. But, by definition, the human will is finite, and thus not omnipotent. It is possible for human agent $S$ to will $p$ and for $p$ not to follow. In other words:

1) The mind does not perceive a necessary connection between S's willing $p$ and $p$.

Malebranche then says, 'but when one thinks about the idea of God, i.e., of an infinitely perfect and consequently all-powerful being, one knows there is such a connection between His will and the motion of all bodies, that it is impossible to conceive that He wills a body to be moved and that this body not be moved' (LO, 448). Hence, we get the following:

2) The mind does perceive a necessary connection between God's willing $p$ and $p$.

From 1) and 2) we can conclude the following: ${ }^{7}$

3) The mind perceives necessary connections only between the will of an infinitely perfect being and its effects.

Lastly, we introduce:

(NC) $c$ is a true cause of $e$ iff the mind perceives a necessary connection between $c$ and $e$.

(C) 'Therefore, it is only God who is the true cause and who truly has the power to move bodies' (LO, 450). ${ }^{8}$

\footnotetext{
${ }^{7}$ Keep in mind that bodies have already been eliminated as candidates for causal efficacy.

${ }^{8}$ Malebranche reiterates this in the Treatise on Nature and Grace, Discourse I, pt. 1, xii: 'This idea of the infinitely perfect Being contains two attributes which are absolutely necessary in order to create the world - a wisdom that has no limits, and a power that nothing is capable of resisting. $[\mathrm{H}]$ is power so far makes him the master of all things, and so far independent of the help of everything whatsoever, that it suffices that He will in order that his wills be executed. For one must above all take notice that God has no need of instruments in order to act, that his wills are necessarily efficacious...his power differs not at all from his will' (T, 116), cf. (Pyle 2003, 100).
} 
This argument is based on the idea that one perceives the necessary connections between causes and their effects. Yet Malebranche obviously thinks he has deduced a metaphysical claim about the natural world, namely, that the world itself is devoid of all causal efficacy. A potential worry with this reading of NNC-that explicitly relies on (NC)-is whether we can actually know the content of God's will in order to claim that a purported effect will necessarily follow from an instance of God's will. To give a clearer metaphysical reading of $\mathrm{NNC}$ we have to alter (NC) as follows:

$(\mathrm{A}) c$ is a true cause of $e$ iff there is a necessary connection between $c$ and $e^{9}$

Thus, given our definition of God and the property of omnipotence which He possesses, we can conclude (without appealing to the content of God's will) that it is not possible for God's will to not bring about its effects. Malebranche is using this notion of perceiving in terms of reflecting on the requisite definitions a priori to see what follows and to see what is and is not conceivable. ${ }^{10}$

NNC contains the following feature: it is an argument that uses a conception of causality that consists of necessary connections between two objects or events that have to hold not only without logical contradiction, but also as a matter of logical entailment. So we have to refine (A) as follows,

$\left(\mathrm{A}^{*}\right) c$ is a true cause of $e$ iff i) there is a necessary connection between $c$ and $e$, and ii) the denial of this causal relation implies a logical contradiction. ${ }^{11}$

The second clause of the right-hand side of $\left(A^{*}\right)$ derives from $(\mathrm{LN})$, which implies that for a relation between two events to be causal the purported effect must be logically entailed by the purported cause. In short, Malebranche's theory of causation is to be understood in terms of logical necessitation.

NNC has had an illustrious career which is only matched by few individual arguments throughout the history of philosophy. In addition to Malebranche, it was endorsed by many philosophers from different eras and different backgrounds, such as the Islamic philosopher and theologian al-Ghazali (10581111), Nicholas of Autrecourt (1300-circa 1350), and David Hume via Male-

\footnotetext{
${ }^{9}$ It seems obvious to shift into the (stronger) metaphysical reading of NNC as Malebranche himself denied that we have epistemic access to the content of God's will; see (Church 1970, 91 2) who presents an epistemic objection against the version of NNC that relies on (NC). See (Rome 1963, 170-2) for a response; note (Church 1970) was first published in 1931.

${ }^{10}$ Lee constructs his metaphysical reading of NNC as follows (and I quote):

(A) An event is a true cause if and only if there is a necessary connection between it and its effect.

(B) There are necessary connections only between the will of an infinitely perfect being and its effects.

(C) Therefore, the only true cause is the infinitely perfect being, i.e., God. (Lee 2008, 543).

${ }^{11}$ This last qualification is important for what is to follow in my criticism of the Lee-Pyle interpretation.
} 
branche. ${ }^{12}$ Although it has been argued that there is a line of influence through these philosophers as suggested by Nadler (1996, 448), NNC appears intuitively compelling once one has understood that a necessary connection must hold between two events for a causal relation to obtain. It is a short step to conceiving of cases where one event does not always follow another, and an even shorter step to actually perceiving, in the experiential sense, a necessary connection between two objects. ${ }^{13}$ In this regard, one of its prima facie strengths is its simplicity.

Another prima facie strength of NNC is the fact that it is purely philosophical in nature and not shackled to any theological doctrine or premise. For example, Malebranche derives the conclusion that there is no necessary connection between the will of finite minds and their effects without employing any theological premise, 'although some theological considerations appear as illustrative cases' (Nadler 1996, 453). It is plausible to use examples that omit the presence of God but still give us the possibility of the human will failing to bring about its effects. ${ }^{14}$ To argue against NNC by solely attacking its theological premises and their implications is to overlook its basic thrust and misidentify the real core of the argument. ${ }^{15}$

The starkest departure however from the version of NNC that Malebranche advocated is most evident in the works of Hume, as Jolley remarks,

'Hume parts philosophical company with Malebranche by insisting that the necessary connection which is an essential component of our concept of causality must be construed in psychological, not logical, terms' (Jolley 2006, 119).

Given that I have stressed the philosophical nature of NNC I think its greatest prima facie strength is exemplified in the negative components of the argument that reject the necessary connection between the will of finite minds and their effects and between physical bodies. This is what Hume found so convincing and intuitively attractive in Malebranche, and this is what made Hume's view on causation famous, and what made the Humean denial of necessary connections between contingent existents, which is prominent in metaphysics today, so appealing.

\footnotetext{
${ }^{12}$ Hume advised his friend Michael Ramsay to 'read once over,' inter alia, Malebranche's The Search so as to be prepared for the argument of the Treatise of Human Nature (McCracken 1983, 254).

13 The experiential version of NNC appears explicitly in Méditations chrétiennes (see note 19 below) and was adopted by Hume: 'Now nothing is more evident, than that the human mind cannot form such an idea of two objects, as to conceive any connexion betwixt them, or comprehend distinctly that power or efficacy by which they are united. Such a connexion wou'd amount to a demonstration, and wou'd imply the absolute impossibility for the one object not to follow, or to be conceived not to follow upon the other: which kind of connexion has already been rejected in all cases' (Treatise, I, iii, 14, Hume 1978, 161-2).

${ }^{14}$ For example, 'in the special case of the mind-body relation, it is not logically necessary that my arm should go up when I will to raise it; it is conceivable that I should be suddenly afflicted with paralysis' (Jolley 1990, 229).

15 (Watson 1993) is a prime example of this sort of attack on Malebranche. Watson proceeds to criticise Malebranche on the grounds that Malebranche blurred the boundaries between theology and philosophy to the extent that the necessary connection between God's will and its effect ends up being nothing more than 'empty tautological wordplay' (Watson 1993, 78).
} 
$\int 2$

Lee (2008) articulates a specific interpretation of Malebranche's occasionalism that sees CCC as the stronger argument over NNC. Lee claims that 'given the theological context, the conception of causation expressed in (A) would have seemed rather stipulative to Malebranche's contemporaries and likely given rise to controversy' (Lee 2008, 544). In addition, Lee argues, Malebranche himself realised this problem and pushed CCC to the fore as his major argument for occasionalism. Lee writes, ' $[\mathrm{NNC}]$ appears to fall out of favour for Malebranche and is conspicuously absent in his later major work to deal with occasionalism, Dialogues on Metaphysics and on Religion' (Lee 2008, 540). According to the Lee-Pyle interpretation, Malebranche preferred CCC over NNC because the former "has a strong dialectical advantage over the NNC argument in arguing against "divine concurrentism"' (Lee 2008, 540). The doctrine of continuous creation was held by most 'divine concurrentists' ${ }^{16}$ of the day, whereas (A) was not only stipulative, but simply rejected by Malebranche's opponents. ${ }^{17}$ Out of the two arguments CCC is in better shape because the underlying principle of CCC is accepted by Malebranche's opponents whilst the underlying principle of NNC is controversial and was most likely rejected by Malebranche's opponents.

This is what I take be the crux of the Lee-Pyle interpretation. I have identified two main claims that are made against NNC. Firstly, NNC is absent from the Dialogues, and this absence is evidence for Malebranche's later distaste with the argument. Secondly, (A) is not accepted by Malebranche's opponents because in light of divine omnipotence finite minds and physical bodies are immediately ruled out as true causes. ${ }^{18}$ For the remainder of this section I will address these two claims and argue that if these problems can be met, there is no reason to suggest that $\mathrm{CCC}$ is the stronger argument.

Lee claims that NNC is 'conspicuously absent' from the Dialogues, and that this is sufficient evidence to suggest that Malebranche was unhappy with the argument. But is this really true? Whilst NNC may not be explicitly present in

\footnotetext{
${ }^{16}$ Briefly, divine concurrentism is the view that both God and the creature possess causal efficacy in bringing about effects in the natural world. NB: Leibniz and Suárez were both divine concurrentists. For a detailed discussion of divine concurrentism see (Freddoso 1991).

${ }^{17}$ Lee $(2008,549)$ makes the additional claim that NNC was 'already missing' in the Elucidations of The Search after Truth (hereafter, Elucidations) to support his interpretation. Lee only mentions NNC's absence in the Elucidations in passing and focuses his criticism on the fact that NNC is absent in Malebranche's major piece on occasionalism, the Dialogues. I will not explicitly discuss this claim here as it involves broader interpretive issues. For instance, one can interpret the Elucidations as a piece in which Malebranche sought out objections to his work and responded to them in order to clarify his position. On this view, the Elucidations is seen more as complementing the Search rather than standing as an independent work. Therefore, Malebranche would not have thought it necessary to reiterate his main argument, and so the absence of NNC in the Elucidations is not a reason to favour the Lee-Pyle interpretation. However, more needs to be said about this matter which I cannot discuss here.

${ }^{18}$ To be clear Lee claims that (A) was controversial. He does not mention (A*) and in what follows this qualification is crucial because my criticism of Lee might appear to be merely terminological. I suggest below (in $\$ 3$ ) that Malebranche's opponents accepted something like (A*), so even if Lee understood causality in the stronger form of $\left(\mathrm{A}^{*}\right)$, his argument would still fail. This note is to flag any potential terminological problem that might arise here. Thanks to Walter Ott for bringing this worry to my attention.
} 
the Dialogues as it was in the Search, it is lurking in the background in some of Malebranche's arguments. Indeed, principle (A) is explicitly used in Dialogue VII where Malebranche discusses in detail the causal impotency of finite bodies. If NNC is, after all, implicit in the Dialogues, and (A) is used explicitly, then Lee cannot claim that NNC's absence is evidence that Malebranche himself developed a dislike for the argument. The very fact that it is lurking in the background actually provides evidence that Malebranche was more than happy to rely on it implicitly when presenting CCC, and when writing the Dialogues more generally.

In Dialogue IV, Theodore introduces Aristes to the use of Reason in the case of analysing the nature and properties of the senses, and further, to be cautious of the testimony of one's senses:

VIII. THEODORE. Listen, then, but remember to meditate on what I have just told you about it. When we seek the reason for certain effects, and ascending from effects to causes we come at last to a general cause or a cause which we can easily see involves no relation between itself and the effect it produces or, rather, appears to produce; then, instead of inventing chimeras, we must have recourse to the author of the laws of nature... Because you see clearly that there can be no relation or necessary connection between the disturbances of the brain and particular sensations of the soul, it is evident that we must recourse to a power not found in these two beings (D, 56-7, italics mine).

Theodore presses Aristes on this point of having recourse to God and to His attributes:

X. 5. ... Certainly, if God still acts now, when can we say that He is the cause of certain effects if we are not permitted to have recourse to Him for those general effects, those effects which we clearly see have no essential and necessary relation to their natural causes? (D, 59, italics mine).

XI. There is no necessary relation between the two substances of which we are composed. The modalities of our body cannot, through their own efficacy, change the modalities of our mind. Nevertheless, the modalities of a certain part of the brain... are always followed by the modalities or sensations of our soul, and this occurs solely... as a consequence of the constant and continually efficacious volitions of the author of our being (D, 59, italics mine).

It is clear from these passages in Dialogue IV that Malebranche is appealing to the fact that there is no necessary connection between the modalities of one's body and one's soul. It is another question whether Malebranche derives this conclusion from the fact that we do not 'see' a necessary connection in the experiential sense, or that we do not 'see' through Reason a necessary connection. ${ }^{19}$ The point is that Malebranche is highlighting the lack of necessary con-

\footnotetext{
${ }^{19}$ This issue is not that important as Malebranche uses NNC in the 'experiential' sense in Méditations chrétiennes (OCM, X 48): 'when a body at rest is struck by another body, it begins to move. You can believe here what you see, for it is a fact and the senses are good enough witnesses when it comes to such facts. But you should not judge that bodies have in themselves some moving force, or that they can communicate such a force to other bodies when they strike them, for you see no such thing happen as that' quoted from (Nadler 1996, 462). Also note that the Méditations chrétiennes appeared in 1683 only five years before the Dialogues and might well be considered a later work. Lee gives no clear demarcation as to what constitutes Malebranche's 'early' and 'later' period, or even if there is a 'middle' period.
} 
nection between certain substances because he wants to argue that they are causally inefficacious, and this claim rests on the assumption that causal efficacy entails necessary connection-that is, (A).

There is further evidence that Malebranche is working with (A) in Dialogue VII where he attempts to construct a reductio ad absurdum in support of the causal inefficacy of finite causes. After accepting Theodore's (CCC) argument, Aristes requests that Theotimus challenge Theodore's views:

XII. THEOTIMUS. Here it is. I can certainly understand that a body cannot move itself. But, supposing it to be moved, I maintain it can move another as its true cause, as a cause between which and its effect there is a necessary connection. For supposing that God has not yet established the laws of the communication of motion, certainly there will not yet be any occasional causes... the impact of bodies is not an occasional cause, but a very real and true cause, as there is a necessary connection between impact and whatever effect you choose (D, 118, italics mine).

Aristes is quick to suppress this argument by pointing out that assuming the impenetrability of bodies presupposes the laws of the communication of motion, and this presupposition requires the will of God. In addition, given CCC (as Theodore established earlier), the efficacy of bodies is lost from the outset of the argument. The very status of this argument aside, ${ }^{20}$ the issue here is that Malebranche is implementing (A) precisely at the point where Lee claims Malebranche is revising the cogency of his arguments for occasionalism-the point at which Malebranche supposedly drops the importance of NNC. In sum, my efforts to highlight the significance and the extent to which (A) is explicitly used in the Dialogues throws Lee's textual claim into doubt.

The second problem that Lee raises against NNC is the claim that (A) is not accepted by Malebranche's opponents. Lee's main reason is this,

The problem, as I see it, is rather that this conception of causation, though perhaps plausible in its own right, is too narrow for an opponent of occasionalism to accept, since given divine omnipotence no finite substance could possibly satisfy this condition $(2008,553)$.

So for Lee, (A) is too narrow because it immediately leads to ruling out creaturely causation given that when we consider divine omnipotence we get the untoward consequence that creaturely causation is merely 'occasional' or 'secondary'. But, how does Lee get to this conclusion? If God wills $S$ to $p$, then, of logical necessity, $p$ must follow. So far so good. But consider the case where $S$ wills $p$ and $p$ does not obtain in virtue of God willing not-p. Does it follow that $S$ lacks causal efficacy in this case? Lee does not think so, rather it is possible for $S$ to have causal efficacy and for God to simply 'overpower' $S$ (Lee 2008, 546). Lee concludes,

Given that the affirmation of divine omnipotence prohibits most theists from endorsing any necessarily efficacious causal connection between a creaturely cause and its effect, the conception of cause expressed in premise (A) is unacceptably narrow, from the concurrentist's perspective, in that it rules out creaturely causation in principle. (Lee 2008, 549).

\footnotetext{
${ }^{20}$ Malebranche is actually responding to Fontenelle in this passage. There is a growing literature on this particular passage, see for example (Downing 2005) and (Schmaltz 2008).
} 
But Lee's objection is misplaced. The original question we are attempting to answer concerns the status of $(\mathrm{A})$. In attempting to answer this question Lee introduces cases involving divine omnipotence in order to show that (A) would have been controversial according to divine concurrentists. Such criticism of (A) depends on considerations of divine omnipotence. But these considerations do not show that there is a problem with (A) itself, or that (A) itself would have been controversial. It is not the case that (A) 'rules out creaturely causation in principle'. Lee's criticism tells us that given divine omnipotence it becomes harder to see how finite minds and bodies can be true causes. But this is exactly what NNC is supposed to show us. Thus, Lee's criticism cannot be taken as an objection directly against (A) although it brings out the role that divine omnipotence plays in showing that creaturely causation is 'secondary' or 'occasional'.

In light of Lee's objection more generally, Malebranche does not have to say anything about cases where $S$ wills $p$ and $p$ does or does not obtain in virtue of God willing $p$ or not- $p$, because he need only appeal to the possibility that $S$ wills $p$ and $p$ does not obtain. It would be question-begging on Malebranche's behalf to say that in the case where $S$ wills $p$ and $p$ follows that God willed $p$. Malebranche should be silent in these cases since we are trying to determine the nature of causation and arrive at a metaphysical thesis between conservatism, concurrentism or occasionalism at this stage of the dialectic. For Lee to suggest that Malebranche does in fact need an answer here leads Lee to mistakenly conclude that Malebranche's opponents would not have accepted (A).

In sum, Lee's discussion of these cases where God might or might not overdetermine the positive instances of $S$ willing $p$ is irrelevant to the truth of (A). If anything what Lee's discussion shows is that we get to the occasionalist's conclusion 'too easily'. ${ }^{22}$ But this is neither a mark against NNC nor an objection against (A) itself. NNC just so happens to have an unexpected though undesirable conclusion (for some), akin to many sceptical arguments against the existence of the external world. Malebranche only needs the claim that event $e$ could fail to follow from event $c$. Conversely, to determine whether $c$ is the cause of $e$, we need only conceive that $e$ could not occur without $c$. This general appeal to conceivability also explains why Malebranche does not need to rely on an appeal to divine omnipotence to rule out creaturely causation. We can show that there is no necessary connection between $S$ willing his arm to be raised and that it not be raised due to a further state of affairs that prevents the event of $S$ 's arm being raised. The insight that Malebranche has here is that we do not need to restrict ourselves to cases that involve divine omnipotence.

At any rate, what Lee has failed to do is confront $(\mathrm{A})$ head on and determine whether Malebranche's opponents accepted (A) via textual evidence. As we will see, the claim that Malebranche's opponents rejected (A) and thought it controversial is untenable.

\footnotetext{
${ }^{21}$ Thanks to an anonymous referee for pressing me on the clarity of my response to Lee's objection.

${ }_{22}$ Pyle might be interpreted as making this point in passing when he says, 'If a true cause must be necessarily connected with its effect, it is easy to show that only the will of God can be such a cause' $(2003,100)$.
} 
Did Malebranche's opponents really reject $(\mathrm{A})$ ? Lee does not mention explicitly who he has in mind that would reject (A), so it seems he is making a broad claim about divine concurrentists. However, such a broad claim is outright false, as Michael Della Rocca remarks,

the view that causation is necessary connection held sway in philosophy. Indeed, for some time a prominent view was even the stronger view... that the necessary connection between cause and effect is a conceptual connection. This stronger view is stronger because it entails that it is not conceivable that the cause exists and the effect does not, whereas the weaker view does not have this entailment. (The stronger position is held, in different ways, by Malebranche, Spinoza, and Leibniz) (Della Rocca 2008, 235).

Robert Sleigh also points out that something like (A) 'was common ground among the Rationalists' $(1990,171)$, and Jolley reiterates that 'in the period before Hume there was nothing eccentric about Malebranche's analysis of the concept of causality; and to many readers this argument for occasionalism must have appeared a powerful one' $(1990,229)$.

In this section, I argue that 1) Spinoza and Suárez accepted (A*), 2) Leibniz accepted that causation is to be understood in terms of necessary connections but that such connections are only physically necessary, and 3) Régis only reacted to the premise that there are no necessary connections between contingent existents and presumably accepted the principle that causation is to be understood in terms of necessary connections, but that it is uncertain whether he drew a distinction between physical and metaphysical necessity. By exploring the ways in which Malebranche's opponents reacted to NNC, we can begin to gain a sense in which NNC was part of an active debate and not based on an eccentric view of causation held only by Malebranche.

Spinoza was a prominent Cartesian and contemporary of Malebranche. At the very outset of the Ethics, Part One, Spinoza states the view that causation is to be understood in terms of logical necessitation. Indeed, he introduces it as an axiom built into his metaphysical system. He writes,

'A3: From a given determinate cause the effect follows necessarily; and conversely, if there is no determinate cause, it is impossible for an effect to follow' (1994 [1677], 86)

Spinoza is thinking of causation as a relation between two events that is connected by logical necessity, the denial of which implies a logical contradiction. Spinoza later argues in Part One, Proposition 17, Scholium 1 against his (potential) opponents in the following way,

Others think that God is a free cause because he can (so they think) bring it about that the things which we have said follow from his nature (i.e., which are in his power) do not happen or are not produced by him. But this is the same as if they were to say that God can bring it about that it would not follow from the nature of a triangle that its three angles are equal to two right angles; or that from a given cause the effect would not follow-which is absurd (Spinoza 1994 [1677], 98, original italics). 
Spinoza is identifying the relation of causality as inherently logical in character such that the denial of a causal relation would imply a logical contradiction, and this is nothing more than $\left(\mathrm{A}^{*}\right) .^{23}$ This is but one instance of Malebranche's major opponents accepting the main premise of NNC. Malebranche is beginning to look less isolated than the Lee-Pyle interpretation makes him out to be.

According to Sleigh, the following thesis was a common rationalist principle: ' $x$ is a real cause of $\mathrm{E}$ only if there is some state $\mathrm{C}$ of $x$ such that, necessarily, if C obtains then E obtains' (Sleigh 1990, 171). There is however the pertinent question of how this kind of necessity is to be interpreted. As we saw for Malebranche, the kind of necessity involved is metaphysical necessity. But for others, in particular Leibniz, the notion of necessity is understood differently. Leibniz responded to NNC as follows:

Malebranche's strongest argument for why God alone acts reduces to this in the end - a true cause is that which the effect follows from necessarily, but an effect follows necessarily from the will of God alone [therefore, etc.]. However, it should be noted that if the state of any entity is known perfectly, then the state of any other entity can be inferred infallibly (although not, I grant, necessarily, i.e., not in such a way that it could ever be demonstrated that the contrary implies a contradiction, since analysis goes on ad infinitum.); quoted from (Sleigh 1990, 171, original italics). ${ }^{24}$

Setting aside the fact that Leibniz cites NNC as 'Malebranche's strongest argument', he denies that the kind of necessity in the common rationalist principle noted above involves logically necessary connections by drawing a distinction between metaphysical and infallible necessary connections. Leibniz's doctrine of infinite analysis is invoked here to argue that if $\mathrm{C}$ obtains, $\mathrm{E}$ can only be inferred infallibly. It will be instructive to briefly see how this response works.

The doctrine of infinite analysis says that if state $\mathrm{C}$ of entity $x$ is contingent, any analysis of $\mathrm{C}$ of $x$ will proceed ad infinitum for there will always be a further reason to explain what grounds $\mathrm{C}$ of $x$ or what grounds a more fundamental entity that has being shown to ground $\mathrm{C}$ of $x$. If the analysis proceeds ad infinitum, one can never have a complete demonstration. By contrast an analysis of a necessary proposition, such as, $2+2=4$ will encounter some identity statement and so reach the end of the analysis, that is, reach the ultimate ground of the explanation. Now take a case of causation which involves finite entities, say, billiard ball $A$ striking ball $B$. Given that it is contingent, our analysis will never give us a complete demonstration. ${ }^{25}$ Therefore, we cannot conclude that the contrary implies a logical contradiction. Therefore, according to Leibniz, we cannot infer that there is no causal relation between $\mathrm{C}$ and $\mathrm{E}$ if our criterion of causation amounts to deriving a logical contradiction. The doctrine of infinite analysis precludes us from making such metaphysical judgements about contingent entities and the relations that hold between them.

\footnotetext{
${ }^{23}$ See (Bennett 1984, ch. 2; 1996, 61) for a fuller discussion of Spinoza's view of causation which Bennett labels as 'causal rationalism'. Curley $(1969,45-6)$ makes a similar claim.

${ }^{24}$ Translated from (Robinet 1955, 412).

${ }^{25}$ It is true that an analysis in this particular causal case may result in a causal chain ultimately grounded in God's initial act of creating this particular world. But given that we are finite beings, we are not able to grasp this chain of explanation. It is for God to 'traverse' alone with 'one stroke of mind' (Leibniz 1989, 28). See Leibniz's On Contingency.
} 
Leibniz's response to NNC depends on the plausibility of his doctrine of infinite analysis and the subsequent distinction he draws between metaphysical and infallible necessary connections. Although a further assessment of Leibniz's doctrines will prove fruitful, the relevant point is that his reaction to NNC does not consist in denying that causal connections involve necessary connections. Leibniz did not assert that it is not the case that necessarily if $\mathrm{C}$ obtains, then $\mathrm{E}$ obtains. Instead he denied that the type of necessitation must consist in logically necessary connections. It is in this way that Leibniz denies $\left(\mathrm{A}^{*}\right)$, the thesis that true causation involves logically necessary connections, whilst retaining the idea that causation involves some kind of necessitation. ${ }^{26}$ It is this 'common ground' between Malebranche and Leibniz that I wish to highlight as it shows that their principles of causation are centred on a common notion that is only interpreted differently due to independent theses.

Pierre-Sylvain Régis (1632-1707), another contemporary Cartesian of Malebranche, directly responded to NNC. He was compelled to do so because of his acceptance of causation in terms of necessary connections. Régis, unlike Malebranche, rejected the lure of the occasionalist doctrine. Instead, Régis accepted the mechanist worldview but conjoined it with divine concurrentism. What is interesting about Régis and his particular blend of Cartesianism is that he witnessed fellow Cartesians, such as Malebranche, embrace the view that God is the only true cause, a view which he rigorously resisted. As a result, Régis took the arguments for occasionalism seriously and is one of the few contemporary philosophers of Malebranche that directly engaged NNC-as we saw, Leibniz mentioned it in passing ('in a private note, not intended for publication' (Sleigh 1990, 171)).

Régis was concerned with how Malebranche formed the premise that there are no necessary connections between the will of finite minds and their effects, and that there are no necessary connections between physical objects or events. Régis responded to NNC by denying the claim that the mind does not perceive necessary connections between two bodies causally interacting:

We should not say that we see no necessary connection between the second causes and the effects we attribute to them, such as we see between the first cause and its effects. For unless we renounce the senses and reason, one sees an obvious connection. We see, for example, that the production of flour is necessarily connected with the way in which the mill changes the motion of the water and wind that comes immediately from God (Régis 1996, 414-5); quoted from (Ott 2008, 10).

On Régis' view, substantial forms are replaced with functional equivalents that are reduced to the mode of the body or substance. In addition, the causal power of a body originates from its microphysical parts. ${ }^{27}$ Since it is impossible for us to know these microphysical parts and the properties they possess, we lack epistemic access to the origin of the causal powers of bodies. Thus, when

\footnotetext{
${ }^{26}$ Elsewhere Leibniz alludes to a distinction between absolute (metaphysical) necessity and physical necessity which allows him to talk about absolute and 'derived subordinate' laws of nature, and hence claim that causation between contingent existents is captured by physical necessity. See Leibniz on Necessary and Contingent Truths (Leibniz 1973 [1686]).

${ }^{27}$ (Régis 1691, 392). For a fuller discussion of Régis' mechanistic view, see (Ott 2008, 11).
} 
we try to conceive of a possible state of affairs in which one object fails to cause the other, we do not really conceive of such a state of affairs. ${ }^{28}$

Régis' strategy is to deny the lack of necessary connections between contingent existents. He was less concerned with attacking Malebranche's conception of causation and instead worked within the 'spirit' of understanding causation in terms of necessary connections. From the text it is unclear whether Régis endorsed a conception of causation that involved logically necessary connections or a weaker view that understands causation in terms of a different notion of necessity, as we saw with Leibniz. Given that Régis claimed that we do see a necessary connection between the production of flour and the mill, which he labelled as 'second causes and effects', the notion of necessity involved could be bound to the laws of nature and thus merely physical. If this is right, it is uncertain whether the notion of necessity is metaphysical or physical. But this is beside the point. What is relevant is the fact that Régis was working within the 'spirit' of $\left(\mathrm{A}^{*}\right)$ and accepted something significantly continuous with it that involved some kind of necessitation, contrary to the Lee-Pyle interpretation.

Last but not least, Suárez also held that causation is to be understood in terms of logical necessitation and he was explicitly one of Malebranche's targets. To see this we need to look at the Suárezian framework briefly. On Suárez's view, if object $o_{1}$ has causal (active) powers $c_{1}$, and God concurs, then the effect of the relevant object will necessarily follow. For it to not follow would lead to contradiction, that is to say, the denial of the causal relation would imply a logical contradiction. Thus, for some scholastics, the substantial forms of an object logically entail its causal powers-it would be logically impossible for the effects of the cause to not follow once the requisite conditions are satisfied. Suárez writes,

if God had decided on his own part to grant his concurrence and had left all the other required conditions intact, then he would have been unable to prevent the action. For it involves a contradiction to remove that which is natural in the absence of any contrary efficient causality, or at least without withholding the assistance or efficient causality that is required on God's part (MD 19:1; Suárez 1994 [1597], 281).

\footnotetext{
${ }^{28} \mathrm{I}$ am not sure whether Régis' response to NNC is successful because he is only objecting to our lack of perceiving necessary connection between two bodies. What are we to say about mind-body causation? There is also a further worry-if the causal power of a body comes from its microphysical parts, how are we to perceive necessary connections in the first place? There is the more general objection that could be potentially raised against Malebranche here that questions his (alleged) assumption that we can ignore things of which we have no idea but that might be causes. Malebranche argues that we have ideas only of mind, body, and God, and that because minds and bodies are not causes and God is a cause, then only God is a cause. But, so the objection goes, there might exist things of which we have no idea that might be causes. Thus, how are we to conclude that God is the only true cause? The response which I think Malebranche would favour is to say that his Cartesian ontology of minds, bodies and God simply excludes other kinds of things of which we have no ideas or that those kinds of things fall into one of the three ontological categories that make up Malebranche's ontology, so there are no things of which we have no idea which are possible causes. Or he could have just meant that his ontology is open for revision. Full evaluations of this kind of objection and, in particular, of Regis' response to NNC are outside the scope of this paper and cannot be included here due to space. However, for an excellent overview of NNC and this particular problem see (Cunning 2008); and for a discussion of Régis' response see (Ott 2008). Thanks to an anonymous referee for bringing this objection to my attention.
} 
Conversely, if God wanted to prevent a certain effect from occurring $\mathrm{He}$ would have to negatively act by withholding his concurrence because, 'even God himself does not seem to be able to bring it about in the composed sense (as they call it) that a cause which by its nature acts necessarily should fail to act once all the things required for acting have been posited' (MD 19:1; Suárez 1994 [1597], 281).

The 'composed sense' I assume refers to the total cause, which consists of God's concurrence with the given object as one cause and the object itself (and/or its accidents) as the other. Thus, Suárez is committed to causal necessity being understood in terms of logical necessitation, which is to say, he is committed to (LN) $-x$ is causally necessary only if the denial of $x$ implies a logical contradiction. The issue surrounding a possible response by Suárez is of my least concern here. Rather I am concerned with highlighting the fact that Suárez accepted the main premise of NNC and that Malebranche, among others, was influenced by this Aristotelian framework of causation involving logically necessary connections. This confirms Della Rocca's conclusion that,

both Malebranche and the typical Aristotelians are actuated by the view that causes - taken on their own - explain their effects... Because of this shared commitment to seeing causes as making effects intelligible, the occasionalists can be seen as among the heirs to the Aristotelian tradition, despite the considerable differences between these two approaches (Della Rocca 2008, 238).

Malebranche is not plucking $\left(\mathrm{A}^{*}\right)$ out of nowhere nor is he operating in a vacuum. On the contrary Malebranche is ingeniously using his opponent's own principles against them in light of the new mechanistic science to argue that God is the only true cause in the world, and that all other objects are merely occasions on which God performs the necessary means to produce the desired effect. It is simply not true that Malebranche isolated himself with a strict connection between causal and logical necessity in virtue of his obscure philosophical and theological framework that many would regard as too demanding. If Malebranche's opponents accepted the main premise of NNC, it becomes a powerful and persuasive argument. Thus, we have reason to accept the JolleyLoeb over the Lee-Pyle interpretation.

I have shown that NNC is a lot stronger than has been thought and that Malebranche did not abandon it because of its alleged weakness. However, there is a growing consensus in the secondary literature that in the midst of presenting NNC Malebranche conflated or equated causal with logical necessity and that by conflating these two kinds of necessity Malebranche made a grave error. Jolley who is a proponent of the interpretation that NNC is Malebranche's strongest argument argues that this conflation was NNC's biggest downfall. Jolley writes, '[b]ut Malebranche's mistake, if it is one, is not a mere surface muddle; it is a mistake of a deep kind' $(1990,229)$. This objection is more serious than the objections posed by the Lee-Pyle interpretation since Malebranche's opponents can accept that causation involves necessary connections but that these necessary connections are of a distinct kind from that of logical necessity. This 
would allow Malebranche's opponents to deny that the absence of logical necessity entails the absence of causal necessity. As we saw in (\$3), Leibniz attempted a similar strategy with his doctrine of infinite analysis.

According to Nadler, if one identifies causal with logical necessity, then one can infer that if there is no logical necessity, then there is no causal necessity. This would permit Malebranche to find an instance of an absence of logical necessity and then infer an instance of an absence of causal necessity. But, the objection goes, what entitles Malebranche to identify causal with logical necessity? Nadler sums up the worry as follows, 'Malebranche's identification of causal with logical necessity does seem strange today, and, I suggest, should have seemed strange to a seventeenth-century Cartesian' (Nadler 2000, 114, original italics). So, not only do we in our modern stand point (supposedly) regard this conflation as a grave mistake on behalf of Malebranche, but also according to Nadler seventeenth-century Cartesians should have been equally perplexed and would have arrived at the same conclusion.

This discussion of whether or not Malebranche conflated causal with logical necessity is relevant here because Lee could argue in response to my objections that if causation is understood in terms of logical necessitation, then it follows that causal necessity is conflated with logical necessity. Malebranche's opponents however regard this conflation as a 'strange' thesis and would have rejected it. So, causation understood in terms of logical necessitation has unacceptable consequences and thus ends up being a controversial thesis. Furthermore, I suspect that it is this thesis that is the main origin of the reservations about NNC. Commentators, such as, Lee, Pyle and Nadler tend to think that not only did Malebranche suppress NNC in his later works, which I argued is false, but that it was, philosophically speaking, a good thing that he did since NNC dubiously conflates or equates causal with logical necessity. ${ }^{29}$

However, Nadler's objection is problematic in two ways. First, to say that this identification of causal with logical necessity should have seemed strange to Malebranche's fellow Cartesians also depends on the assumption that they were aware of this distinction and that they clearly understood what causal necessity amounted to and what the genuine differences were between the two. ${ }^{30}$ But, this assumption is dubious. As we saw in $(\$ 3)$ Régis did not explicitly object to characterising causation in terms of logical necessitation, whilst Spinoza did not draw a distinction between causal and logical necessity. Indeed only '.. since Hume it has been widely thought that what is causally possible is only a fragment of what is logically or absolutely possible' (Bennett 1984, 29). ${ }^{31}$ In short,

\footnotetext{
29 Thanks to an anonymous referee for helping me highlight this point.

${ }^{30}$ I should point out that Nadler does not tell us what causal necessity is supposed to be and simply assumes that causal necessity is obviously something other than logical necessity.

${ }^{31}$ To be fair, Nadler in his (1996) does provide a reason to think that there is a distinction between causal and logical necessity available but only refers to Aquinas and William of Occam to support this claim. Nadler thinks that if Malebranche is arguing against the Aristotelian causal framework, then Malebranche has overlooked these 'developments'. But as we saw in $(\mathbb{S} 3)$ Malebranche was reacting, in part, to Suárez. So it is not clear what these 'developments' amounted to. Nadler believes that these so called 'developments' rest on the claim that God could have done otherwise by establishing a 'different natural order'. Whether or not this thesis was controversial, it cannot be decreed that there is now a genuine distinction between causal and logical necessity that becomes a benchmark that everyone must acknowledge, nor did philosophers who accepted this claim necessarily think that it implied a commitment to two genu-
} 
Malebranche cannot be accused of conflating causal necessity with logical necessity because there wasn't really a well-defined distinction here to begin with. Second, for Nadler to simply focus on seventeenth century Cartesians fails to appreciate the breadth of NNC and the extent to which this argument applied to philosophers other than Cartesians. For example, in the Search and the Elucidations, Suárez was amongst Malebranche's targets, and as established earlier was a great influence on Malebranche.

If there is anywhere we can press on NNC, it is the claim that causal necessity is nothing over and above logical necessity or absolute necessity, depending on what we take to be the strongest form of necessity. But that is only due to our somewhat refined conceptual machinery that Malebranche did not possess. From our stand point it is unfair to charge Malebranche with such a mistake. As Bennett puts it, though referring to Spinoza,

'It is a theory of ours, these days, that causal necessity is weaker than absolute necessity; it is not trivially or obviously true, nor has it been well supported by arguments based on clearly good accounts of the two sorts of necessity' (Bennett 1984, 30). ${ }^{32}$

However, when we put the alleged anachronistic response to one side I still want to resist such a condemnation of Malebranche and suggest an interpretation of NNC that rebuts Nadler's objection directly. The basic thrust of Nadler's objection boils down to this. Given that there is a genuine distinction between causal and logical necessity (and let us suppose that there is such a distinction for the sake of argument), Malebranche conflates or equates causal and logical necessity. In addition, by understanding causation in terms of logical necessitation, what is causally necessary becomes identified with what is logically necessary. ${ }^{33}$

But, even if there is this distinction and Malebranche understands causation in terms of logical necessitation, it does not follow that causal necessity is equated with logical necessity. Whilst it is true that Malebranche's account of causation allows him to claim that 'where there is no logical necessity there is no causal necessity' (Nadler 1996, 462), causal and logical necessity remain distinct. ${ }^{34}$ Why? They remain distinct because Malebranche denies the inference that if there is a logically necessary connection between $c$ and $e$, then there is a causally necessary connection. To put it another way, were causal necessity to be equated with logical necessity, Malebranche would have accepted the inference that where there is logical necessity, there is causal necessity. But he does not. Rome notices this widely overlooked subtlety in Malebranche, which is worth quoting in full,

ine and distinct kinds of necessity. This aside, Nadler's references to Aquinas and Occam are rather weak given what is at stake.

${ }^{32}$ See for instance (Shoemaker 1998) who argues for the thesis that causal necessity is a 'special case' of metaphysical (absolute) necessity.

${ }^{33}$ A charitable reading of Nadler would amount to construing Nadler's objection as claiming that Malebranche made the problematic assumption that causal necessity is just as strong as logical necessity rather than accusing Malebranche of actually conflating causal with logical necessity. Although Nadler does say that there is a conflation of causal and logical necessity, Nadler might be charitably understood as objecting to the 'logical-tightness' of the causal connections used in NNC. Thanks to an anonymous referee for highlighting this point.

${ }^{34}$ The contrapositive also holds, viz., if there is a true causal relation, it is logically necessary. 
Therefore when Malebranche asserts that in the case of a true cause there is logical necessity between effect and cause, he means (1) that absence of logical necessity indicates the absence of creative causality proper. Necessity is a necessary condition for the operation of causal creative power. And presence of true causality implies logical necessity. But (2) where we do find logical necessity, we cannot ipso facto infer that true causality proper is present (Rome 1963, 179 , original italics).

Causal necessity cannot be identified with logical necessity. Malebranche is committed to causation being understood in terms of logical necessitation, but this is not to say that causal necessity is reduced to logical necessity and certainly does not imply any equivalence between the two. Thus, Malebranche cannot be accused of conflating causal and logical necessity. Malebranche never said that causation is nothing but logical necessity, and as Rome further remarks, 'such logical necessity, ..., is quite distinct from creative causality, from the origin of matters of fact' $(1963,179)$. But how exactly are they related?

When we consider two billiard balls colliding at the pub or an instance of us willing to drink a beer, logical necessity is not perceived for we can conceive of states of affairs where the two balls do not collide and where we fail to drink. Thus, there is no causal relation between the two balls or our will to drink and the event of us drinking a beer. When it comes to God's will, we do perceive logical necessity, 'but we do not therefore infer His causal power' (Rome 1963, 179, original italics). For instance, we do not apprehend that God's will is necessarily efficacious because it follows from the very definition of God. To deduce that God is a true cause we must apprehend 'the active presence of God's causal will' (Rome 1963, 179, original italics). But what does this mean? Suppose God wills $p$ and $p$ obtains. We do not thereby perceive two distinct existents: God and then $p$. Instead we perceive God's will making or creating $p$. That is, we just perceive God's will in action, and because it is just God's will creating and making a given effect it is inconceivable that $p$ does not obtain when God wills $p .^{35}$ According to Malebranche, we see God's causal power when we apprehend His divine will in action. In order to see God's will in action we must see its effects. So, only by understanding the effects of true causes can we truly grasp causality. ${ }^{36}$ Thus, by perceiving a logical necessity we do not perceive a causal necessity, which is to say that we cannot infer causal necessity from logical necessity. But we can infer the absence of causal necessity from the absence of logical necessity, and it is this inference that lies at the heart of NNC.

\footnotetext{
${ }^{35}$ The deeper explanation of why we cannot infer causal from logical necessity, I suspect, depends on other metaphysical theses that Malebranche is independently committed to, theses such as that the world ontologically depends on God's will and his conception of God as Existence and Creator. Malebranche's denial of Descartes' doctrine of the creation of the eternal truths and essences and Malebranche's doctrine of the vision in God are also relevant here. However, a discussion of these doctrines is beyond the scope of this paper. For discussion of Malebranche's doctrine of the vision in God, see (Schmaltz 2000).

${ }^{36}$ Rome writes, 'While we cannot pass by necessity from cause to effect as would be required in a philosophy of efficient essential causality, we can, with true causality, as Malebranche construes it, pass from effect to necessary cause' (1963, 180). For Rome's discussion of NNC, see (Rome 1963, 179-82).
} 


\section{REFERENCES}

Bennett, J. 1984. A Study of Spinoza's Ethics. Indianapolis, IN: Hackett.

-. 1996. 'Spinoza's Metaphysics.' In The Cambridge Companion to Spinoza, ed. D. Garrett. Cambridge: Cambridge University Press.

Church, R. 1970. A Study in the Philosophy of Malebranche. London: George Allen and Unwin.

Cunning, D. 2008. 'Malebranche and Occasional Causes.' Philosophy Compass $3(3): 471-90$.

Curley, E. 1969. Spinoza's Metaphysics: An Essay in Interpretation. Cambridge, MA: Harvard University Press.

Della Rocca, M. 2008. 'Causation Without Intelligibility and Causation Without God in Descartes.' In A Companion to Descartes, ed. J. Broughton and J. Carriero. Oxford: Blackwell.

Downing, L. 2005. 'Occasionalism and Strict Mechanism: Malebranche, Berkeley, Fontenelle.' In Early Modern Philosophy: Mind, Matter, and Metaphysics, ed. C. Mercer and E. O'Neill. New York: Oxford University Press.

Freddoso, A. 1991. 'God's General Concurrence with Secondary Causes: Why Conservation is not enough.' Philosophical Perspectives 5: 553-85.

Hume, D. 1978. A Treatise of Human Nature. P. Nidditch ed. Oxford: Oxford University Press.

Jolley, N. 1990. 'Berkeley and Malebranche on Causality and Volition.' In Central Themes in Early Modern Philosophy, ed. J. A. Cover and M. Kulstad. Indianapolis: Hackett.

- 2006. 'Metaphysics.' In The Cambridge Companion to Early Modern Philosophy, ed. D. Rutherford. Cambridge: Cambridge University Press.

Lee, S. 2008. 'Necessary Connections and Continuous Creation: Malebranche's Two Arguments for Occasionalism.' Journal of the History of Philosophy 46(4): 539-66.

Leibniz, G. W. 1973 [1686]. 'Necessary and Contingent Truths.' (M. Morris and G. H. R. Parkinson, Trans.) In Philosophical Writings, ed. G. H. R. Parkinson. London: Dent.

-. 1989. Philosophical Essays. R. Ariew and D. Garber, Trans. Indianapolis: Hackett.

Loeb, L. 1981. From Descartes to Hume: Continental Metaphysics and the Development of Modern Philosophy. Ithaca: Cornell University Press. 
Malebranche, N. 1992 [1680-1]. Treatise on Nature and Grace. P. Riley, Trans. Oxford: Clarendon Press.

- 1997 [1674-5]. The Search after Truth. T. Lennon and P. Olscamp, Trans. Cambridge: Cambridge University Press.

- 1997 [1688]. Dialogues on Metaphysics and on Religion. D. Scott, Trans. Cambridge: Cambridge University Press.

McCracken, C. J. 1983. Malebranche and British Philosophy. Oxford: Clarendon Press.

Nadler, S. 1996. '"No Necessary Connection": The Medieval Roots of the Occasionalist Roots of Hume.' The Monist 79(3): 448-66.

-. 2000. 'Malebranche on Causation.' In The Cambridge Companion to Malebranche, ed. S. Nadler. Cambridge: Cambridge University Press.

Ott, W. 2008. 'Régis' Scholastic Mechanism.' Studies in History and Philosophy of Science 39: 2-14.

Pyle, A. 2003. Malebranche. London: Routledge.

Régis, P.-S. 1691. Cours entier de philosophie ou Système général selon les principles de Descartes. 2nd ed. Amsterdam: Huguetan.

- 1996. L'usage de la raison et de la foi. Armogathe ed. Paris: Fayard.

Robinet, A., ed. 1955. Malebranche et Leibniz: Relations personelles. Paris: J. Vrin.

Rome, B. 1963. The Philosophy of Malebranche. Chicago, IL: Henry Regnery Company.

Schmaltz, T. 2000. 'Malebranche on Ideas and the Vision in God.' In The Cambridge Companion to Malebranche, ed. S. Nadler. Cambridge: Cambridge University Press.

- 2008. 'Occasionalism and Mechanism: Fontenelle's Objections to Malebranche.' British Journal for the History of Philosophy 16(2): 293-313.

Shoemaker, S. 1998. 'Causal and Metaphysical Necessity.' Pacific Philosophical Quarterly 79(1): 59-77.

Sleigh, R. 1990. 'Leibniz on Malebranche on Causality.' In Central Themes in Early Modern Philosophy, ed. J. A. Cover and M. Kulstad. Indianapolis, IN: Hackett.

Spinoza, B. 1994 [1677]. A Spinoza Reader: The Ethics and Other Works. E. Curley, Trans. Princeton, NJ: Princeton University Press. 
Suárez, F. 1994 [1597]. On Efficient Causality: Metaphysical Disputations 1719. J. Freddoso, Trans. New Haven: Yale University Press.

Watson, R. 1993. 'Malebranche, Models, and Causation.' In Causation in Early Modern Philosophy: Cartesianism, Occasionalism, and Preestablished Harmony, ed. S. Nadler. University Park, PA: Pennsylvania State University Press. 